\title{
Nuisance Activities of Straw Colored Fruit Bats (Eidolon helvum) on the University of Energy and Natural Resources, Ghana
}

\author{
Agyei-Ohemeng, James ${ }^{1 *}$; Adu Yeboah, Bright ${ }^{1}$; Asamoah, Francis Boafo ${ }^{1}$; Opoku Ohemeng, Mordecai ${ }^{2}$ \\ ${ }^{1}$ Department of Ecotourism, Recreation and Hospitality, University of Energy and Natural Resources, Sunyani, \\ Ghana \\ ${ }^{2}$ Department of Mathematics, University of Energy and Natural Resources, Sunyani, Ghana \\ Email: james.agyei-ohemeng@uenr.edu.gh
}

\begin{abstract}
Different nuisance behaviors by wild animals through their activities have been reported in the world where humans and wildlife have been living in the same habitat and sharing resources. In these study activities of straw colored fruit bats (Eidolon helvum) were observed and recorded on the University of Energy and Natural Resources campus in Ghana using direct observation and survey questionnaires. From the results of the study it was observed that at high population densities, the most nuisance activities caused on the respondents (90) were dropping of urine, $(\mathrm{N}=45 ; 50 \%$; $\left.\mathrm{x}^{2}=6.52, \mathrm{p}=0.04\right)$, excreta $\left(\mathrm{N}=45 ; 50 \% ; \mathrm{x}^{2}=6.52, \mathrm{p}=0.04\right)$ and all respondents did not like the marking of walls of the University with their excreta. At the same time $49 \%$ of respondents (210) did not like the noise during roosting while $48 \%$ disliked their activities causing breaking of branches and $43 \%$ were against defoliating of trees causing environmental damages to the roost trees at high population. Meanwhile it was observed that these activities coincide with their migration periods. During the low population occupancy, the students are on holidays. These activities of bats are therefore considered nuisance and therefore proper management of these bats are needed to control them.
\end{abstract}

Keywords: Population, habitat, fruigivores, resources, environmental, excreta

\section{Introduction}

The straw-colored fruit bat, Eidolon helvum [1], is a Frugivorous animal in the order Megachiroptera [2]. Although traditionally not viewed as a charismatic species, bats are an invaluable natural resource. Nearly 1,000 different kinds of bats are known today, fully one-quarter of known mammal species. Despite their diversity, the world's only flying mammals remain among the least understood of animals $[3]$.

Centuries of myth and superstition have made bats among the world's least appreciated wildlife. Decades of unwarranted human fear, misinformation, and persecution of bats at their roosts have pressed populations into severe decline nearly everywhere in the world and endangered many species [4]. While for some species of bats it may already be too late, sound management practices can potentially save others.

In West Africa, there are over 120 species of fruits and nectar eating bats, however, in Ghana there are about fifteen (15) fruit eating bats, [5], feeding on a wide range of trees in the forest landscape. They feed on leaves, flowers, and large proportion on fruits of different families of tropical forest plant species. E. helvum is known to feed on the following fruits, both cultivated and wild, (Musaceae) Musa sapientum, (Caricaceae) Carica papaya, (Anacardiaceae) Mangifera indica, (Bignoniaceae) Kigelia aethiopica (Combretaceae) Terminalia sp. [6] (Fujita and Tuttle, 1991). In Nigeria, E. helvum, feeds almost exclusively at night, visiting only trees that have food resources, whereas trees visited during the day are only for roosting [2] (Okon, 1974). They may assist in the pollination of the flowers of some trees [7], but probably not to the same extent as some of the smaller fruit bats [8].

The gregarious habits of these bats probably evolved in conjunction with their ability to forage on many types of food resource; obviously they feed on only one or two food items that could not be sustained in large numbers in one place for more than a short time [8]. 
The straw-colored fruit bat, Eidolon helvum, is eaten in most West African countries [9], but the hunting method is unsustainable. All these contribute to the population decline of wildlife including bats. [10] notes that the peak season reported for hunting bats corresponds with the main dry season in Ghana. This means the bats provide an important food source during the "lean" agricultural season. In Brong Ahafo region, the current spate of hunting of the fruit bat for bush meat sold at Techiman market is very disturbing (Personal observation).

\subsection{Problem Statement}

Straw coloured fruit bat (E. helvum) is classified internationally as near-threatened due to overhunting [11]. Listed under the Migratory Species Convention and on Appendix II of CITES, it is protected under Ghana Wildlife laws and a subject of global animal tracking research. However, bats in Africa are under-studied, underappreciated, and under severe threat, despite their provision of essential ecological services across the continent [7].

The current rate of hunting of E. helvum for bush meat in the Brong Ahaffo Region calls for a monitoring program of a higher magnitude to enhance their conservation. The ecology of the interactions between the population, food resources and their impact on roosting trees would be quite beneficial to investigate as an ecosystem approach into the conservation of E. helvum on the University Campus. This might reduce the nuisance tag by some sections of the University community about these animals.

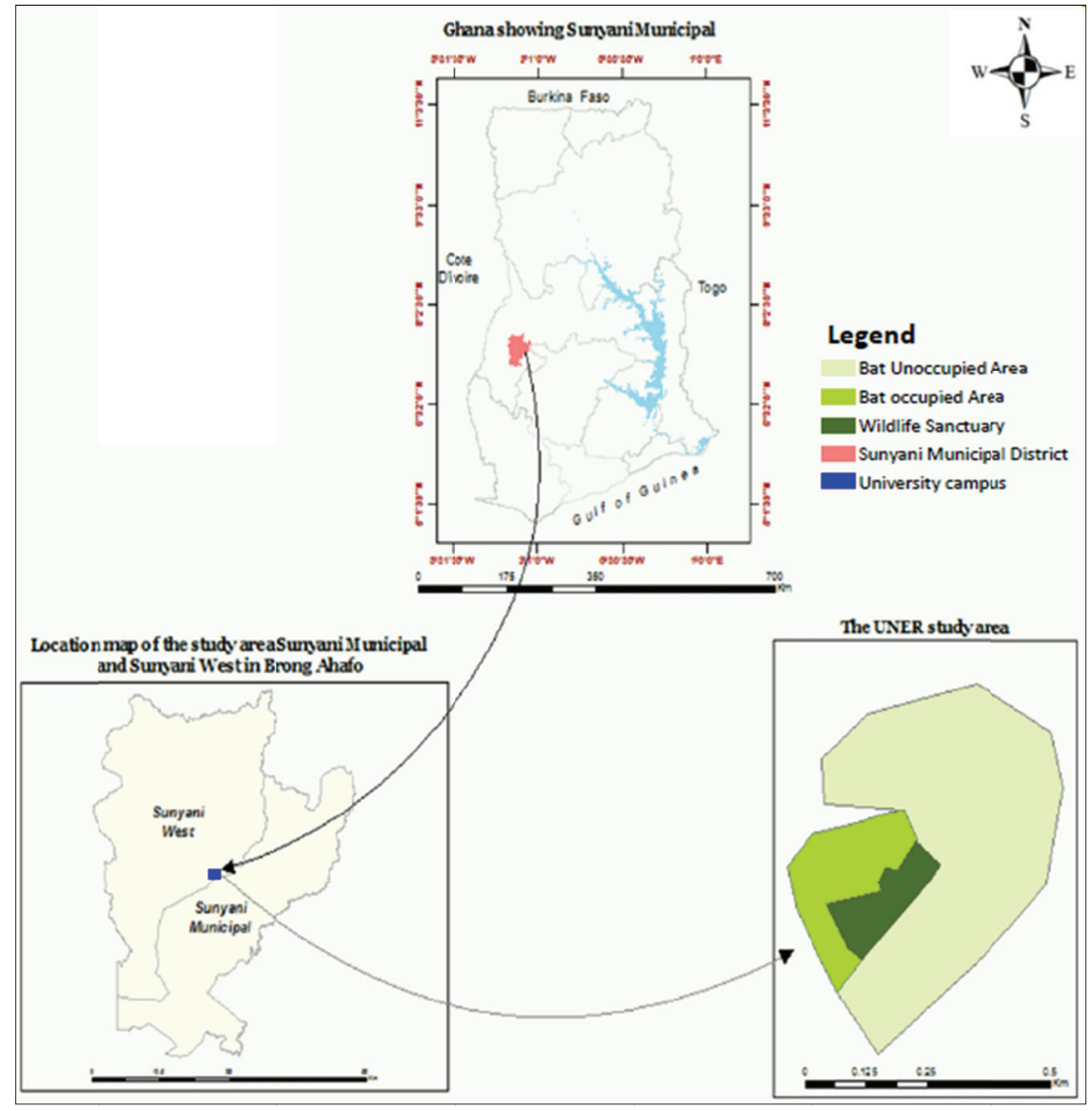

Figure 1. Map of study area

\subsection{Objectives}

This study was commissioned to study the most common nuisance activities brought by straw colored 
fruit bats to students and staff on the University campus. The study also aimed to know the practices and attitude towards bats on the University campus.

\subsection{Study Area}

Sunyani is $400 \mathrm{~m}$ above sea level, and the University of Energy and Natural Resources is located in the Sunyani West District Assembly. The climate is characteristic of the tropical humid zone with two seasons, namely, harmattan and rainy season. Rainfall is bimodal with maximum occurring in May-June and September - October, (Meteorological Services, 2014). It lies between Latitudes $7^{\circ} 20^{\prime} \mathrm{N}$ and $7^{\circ} 05^{\prime} \mathrm{N}$ and Longitudes $2^{\circ} 30^{\prime} \mathrm{W}$ and $2^{\circ} 10^{\prime} \mathrm{W}$ (Figure 1) and shares boundaries with Sunyani West District to the North, Dormaa District to the West, Asutifi District to the South and Tano North District to the East. The University of Energy and Natural Resources covers an area of 120 acres (48.564ha) lies along the Sunyani Berekum highway. It shares a boundary with the Regional Administration and the closest community is Fiapre towards Berekum. It is directly opposite the Seventh Day Adventist Secondary School and Hospital. The campus is laid out with forest tree outgrowths, made up of indigenous tree species like Ceiba pentandra, Triplochiton scleroxylon, and exotic plant species like Eucalyptus grandifolia, Tectona grandis and Senna siamea.

\section{Methodology}

\subsection{Direct Observation}

Direct observations on the nuisance activities were done between October to December 2015 to 2018, during working hours from $0800 \mathrm{hrs}$ to $1700 \mathrm{hrs}$ for 10 continuous days each month to observe the continuous occurrence of measured activities, Lehner, 1992 where students, staff and visitors interact with these bats by walking around the university and parking of vehicles under roosting trees.

\subsection{Survey Questionnaire}

The questionnaire was designed to know the peoples' encounters with the bats and the nuisance activities shown to them. Furthermore the attitudes of people towards the bats were also determined using questionnaires that included questions on deliberate disturbances, hunting of these bats. Three hundred (300) students and staff of the University were encountered during the survey. Privacy and confidentiality were maintained throughout the survey.

\subsection{Data Analysis}

Using a Chi-square test the differences in frequency among the types of nuisance activities and/or between the answers of the respondents were determined. This provided evidence that certain answer or a certain type of nuisance activities is more common than others [12]. All statistics were carried out using Statistical Package for the Social Sciences (SPSS). Statistical significance for all tests was set at P $\leq 0.05$.

\section{Results}

Figure 2 below is a time series of bat numbers on UENR campus, [13], The highest number of counts was in December $(240,000)$ and March $(180,000)$ the lowest counts were in May to October each year, and decreased from May to October what triggers this pattern is not known and should be investigated.

Although there are some information on similar bat fauna in Kumasi and Accra in Ghana [14], Information on their seasonality, roost sites, migration habits, food sources, foraging patterns, or timing of parturition have not been documented. 


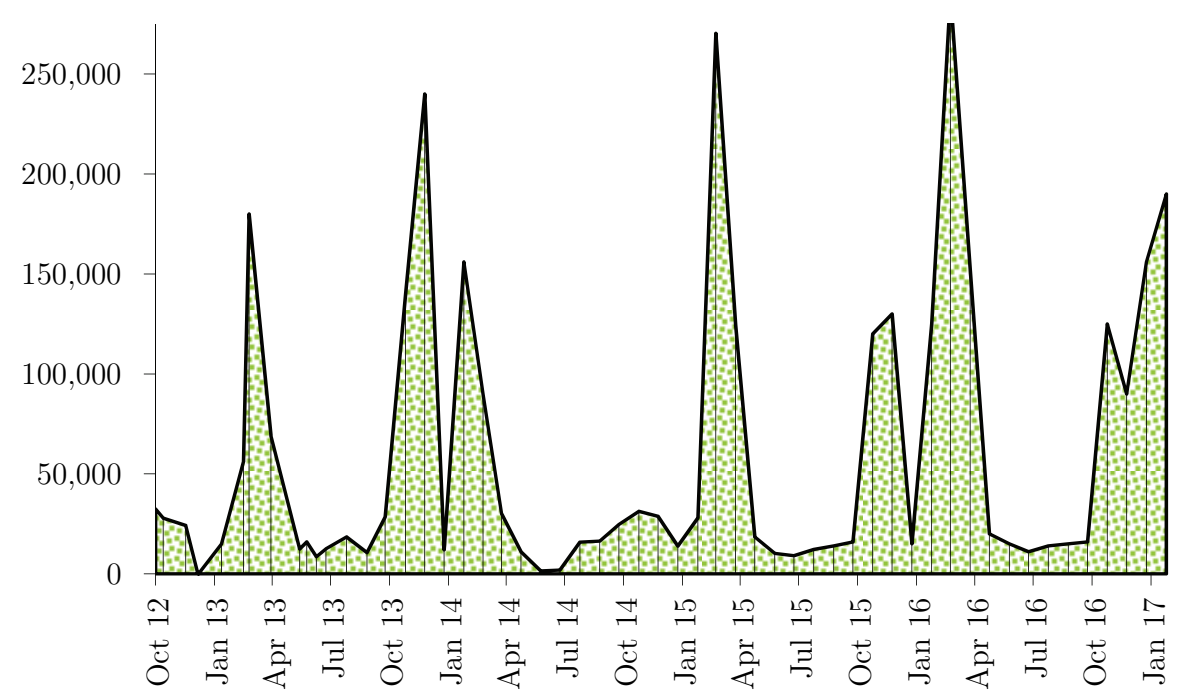

(Source: Eidolon colonies: https://sites.google.com/site/eidolonafrica/home)

Figure 2. Monthly population counts of bats on UENR campus from Oct'12 to Jan'17

Table 1. Nuisance activities towards UENR community members

\begin{tabular}{ll}
\hline Behaviour & Respondents (90) \\
\hline \multirow{2}{*}{ Dropping urine on respondents } & $\mathrm{N}=45 ; 50 \% ;$ \\
& $\mathrm{x}^{2}=6.52$, \\
& $\mathrm{p}=0.04$ \\
\hline \multirow{3}{*}{ Dropping excreta on respondent } & $\mathrm{N}=45 ; 50 \% ;$ \\
& $\mathrm{x}^{2}=6.52$, \\
& $\mathrm{p}=0.04$ \\
\hline \multirow{3}{*}{ Droppings on vehicles } & $\mathrm{N}=35 ; 31 \% ;$ \\
& $\mathrm{x}^{2}=3.43$, \\
& $\mathrm{p}=0.05$ \\
\hline \multirow{3}{*}{ Marking buildings with excreta } & $\mathrm{N}=10 ; 9 \% ;$ \\
& $\mathrm{x}^{2}=0.002$, \\
& $\mathrm{p}=0.005$ \\
\hline
\end{tabular}

Table 2. Effect of bats on the environment

\begin{tabular}{ll}
\hline Effect & Respondents (210) \\
\hline \multirow{3}{*}{ Breaking of branches of trees } & $\mathrm{N}=100,48 \%$, \\
& $\mathrm{x}^{2}=45.72$, \\
& $\mathrm{p}=0.003$ \\
\hline \multirow{3}{*}{ Defoliating tree barks } & $\mathrm{N}=90,43 \%$, \\
& $\mathrm{x}^{2}=42.67$, \\
& $\mathrm{p}=0.002$ \\
\hline \multirow{2}{*}{ Noise from roosting bats } & $\mathrm{N}=103,49 \%$, \\
& $\mathrm{x}^{2}=48.76$, \\
& $\mathrm{p}=0.002$ \\
\hline & $\mathrm{N}=40,19 \%$, \\
Covering of sky after roost disturbance & $\mathrm{x}^{2}=124.56$, \\
& $\mathrm{p}=0.0001$ \\
\hline
\end{tabular}




\section{Discussion}

The University of Energy and Natural Resources in Sunyani, is unique in that it has a large resident fruit bat colony on the campus. Despite the presence of the bats on the site since 2008, ecological studies conducted by the author, [13], [15], and [16], indicate that the population fluctuate monthly, figure 2, and they have had a telling effect on the trees on the campus and affect students and staff population on campus. The ecological studies show that there are bats present on the campus throughout the year. During their high population peaks, they cause a lot of nuisance to students and staff Table 1 and 2 . However, the academic calendars indicate that during their low population periods the University is on break.

Due to the activities of the bats some local residents see them as source of food and hunt them during their high population periods and this is also a nuisance to the University population from stones and occasional gun shots during the week ends.

However, the negative impact of bats on trees through suppression of flowering, fruiting and defoliation, if it continues the forest cover may not be able to support the increasing population of bats in the study site for some time to come. E. helvum feed on the flowers and nectar of many indigenous trees, such as Azadiractha indica, Ceiba pentandra, Deloniix regia, Holarrhena floribunda, Newbouldia laevis, Solanum erianthum, Milicia excelsa, Broussonetia papyrifera. Ficus exasperata, Morus mesozygia, Triplochiton scleroxylon, which they also pollinate.

The E. helvum population had some effect on the trees but with time, during the period of low population from the roost, May-August; the trees may have time to recover even though the period is short. Trees like Ceiba pentandra, and Triplochiton sp. had never seen flowers and fruits throughout the study period, even though their counterparts flower and bear fruits.

Throughout the study there were bats presences in the study area. However, their numbers varied with the months, figure 2 . This could be used to study the life cycle of these bats and at the same time help to design appropriate conservation strategies that will focus on bat population at a particular period. Their night flights can attract bat lovers and the high population months could be used to attract viewing bats in flight.

Through the setting up of a bat research center on the campus this nuisance behaviour could turn into a positive project that can bring in students from other Universities worldwide to look into the secrets of these wild; animals.

\section{References}

1. Kerr (1792) Eidolon helvum; Integrated Taxonomic Information System, Available at https://www.itis.gov/ servlet/SingleRpt/SingleRpt?search_topic=TSN\&search_value=631569\#null

2. Okon, E. E., (1974), Fruit bats at Ife: Their roosting and food preferences (Ife fruit bat project no. 2). Nigerian Field 39(1): 33-40.

3. Vivian, P. (2007), Bushmeat hunting alters recruitment of large-seeded plant species in central Africa. Biotropica 42, 672-679.

4. Bat Conservation International. (1989), Bats: Gentle Friends, Essential Allies. BCI, Austin, Texas.

5. Kankam, B. O., \& Oduro, W. (2009). Frugivores and fruit removal of Antiaris toxicaria (Moraceae) at Bia Biosphere reserve, Ghana. Journal of Tropical Ecology, 25(2), 201-204.

6. Fujita, M. S. \& Tuttle, M. D., (1991), Flying foxes (Chiroptera: Pteropodidae): threatened animals of key ecological and economic importance. Conservation Biology, 5, 455-463

7. Ayoade, O. J.; Oke, S. O. and Omisore, E. O., (2012), The impact of bats on the greens (landscape features): A case study of Obafemi Awolowo University campus, Ile-Ife, Nigeria. Agricultural Science Research Journals 2(7): 405-411.

8. Happold, D.C.D., (1987), The mammals of Nigeria. Clarendon Press, Oxford. Funmilayo, O. (1979). Ecology of the straw-coloured fruit bat in Nigeria Revue de Zoologie Africaine 93:589-600

9. Funmilayo, O. (1979), Ecology of the straw-coloured fruit bat in Nigeria Revue de Zoologie Africaine 93:589-600 i1545-1542-93-5-1393

10. Kamins, A. O.; Restlif, O.; Ntiamoah-Baidu, Y.; Suu-Ire, R.; Hayman, D. T. S.; Cunningham, A. A.;Wood, J. L. N, and Rowcliffe, J. M (2011), Uncovering the fruit bat bushmeat commodity chain and the true extent of fruit 
bat hunting in Ghana, West Africa Biological Conservation Volume 144, Issue 12, December 2011, Pages 30003008

11. IUCN (2010), Red List of threatened species. Website: http://www.redlist.org

12. Sha, J.C.M., M.D. Gumert, B.P.Y.H Lee, L. Jones-Engel, S. Chan \& A. Fuentes (2009), Macaque-Human interactions and the societal perceptions of macaques in Singapore. American Journal of Primatology 71: 825839; https://doi.org/10.1002/ajp.20710

13. Agyei-Ohemeng J. (2015), Aspects of the Ecology of Fruit Bat (Eidolon helvum) in the University of Energy and Natural Resources, Sunyani MPhil Thesis, Kwame Nkrumah University of Science and Technology, Kumasi, Ghana.

14. Fenton, M. B. and Rautenbach, I. L. (1998), Impacts of Ignorance and Human and Elephant Populations on the Conservation of Bats in African Woodlands. In Bat Biology and Conservation: 261-270. Racey, P. A. (Ed.) Washington, D.C.: Smithsonian Institution Press. i1545-1542-93-5-1393

15. Agyei-Ohemeng, J., (2013), Bats: Ghana's best-kept wildlife secret. Daily Graphic,

16. Agyei-Ohemeng, J. \& Danquah, E., (2016), The contribution of fruit bats, Eidolon helvum, to biodiversity on the University of Energy and Natural Resources' campus, Sunyani, Ghana. Journal of Natural Sciences Research 6(8): 74-82. 